\title{
LLEVA MARCA, LLEVA CALIDAD: EL DISCURSO COMERCIAL AMBULANTE EN EL TRANSPORTE PÚBLICO DE BUENOS AIRES COMO GÉNERO DISCURSIVO
}

\author{
Natalia LEISCH \\ Universidad de Buenos Aires \\ Julieta Murata Missagh \\ Universidad de Buenos Aires
}

\section{RESUMEN}

En los últimos años, los estudios sobre la venta ambulante han crecido exponencialmente en el campo de la antropología sociocultural y la sociología (M. Perelman 2013; Stillerman 2015; Shapiro Anjaria 2006). Tales abordajes sitúan el fenómeno de la venta en relación con los ejes de la pobreza urbana, el desempleo y las luchas por el uso del espacio público. Sin embargo, no existe a la fecha un caudal consistente que instrumente herramientas analíticas de tipo lingüístico que permitan abordar este problema como un fenómeno eminentemente discursivo. El presente trabajo propone una aproximación al análisis del llamado «discurso comercial ambulante» (DCA) y del «discurso mendicante» (DM), tal como se efectúa en el medio de transporte más corriente para quienes se dirigen, todos los días, desde el Conurbano sur a la Ciudad de Buenos Aires: el ferrocarril Roca. El artículo se plantea los siguientes objetivos: 1) situar el DCA y el DM como dos géneros discursivos asociados, sujetos a sus propios principios funcionales, sus convenciones discursivas y sus constricciones materiales; 2) relevar la recurrencia de cinco recursos discursivos presentes en DCA: a) el saludo, b) la disculpa, c) el agradecimiento, d) la descripción técnica del producto y e) la evaluación del producto. A partir del análisis de un corpus constituido por 73 transcripciones de interacciones grabadas, nos centramos en las condiciones de producción del discurso comercial y mendicante y sus presupuestos (Hayati y Maniati 2010; Olaosun 2008), los aspectos interaccionales con el público de pasajeros (Goffman 1979), la violencia simbólica y material que estos discursos vehiculizan, así como el uso de estrategias discursivas que tienen como objetivo la persuasión de la venta. La existencia de una escala de productos cuya venta requiere mayor o menor esfuerzo argumentativo, el empleo de catáforas, el repertorio de fórmulas organizadas sobre una estructura retórica relativamente común, el registro comercial-publicitario, la cita de autoridad de la publicidad televisiva, ciertos usos lingüísticos peculiares y la disculpa configuran, según nuestro corpus, una serie de regulari- 
dades estructurales, formales y funcionales estables y a la vez flexibles que nos habilitan a sostener la existencia de un género discursivo de la venta ambulante (Briggs y Bauman 1996).

PALABRAS CLAVE: discurso comercial ambulante, argumentación, análisis del discurso, venta ambulante.

\section{ABSTRACT}

Recent academic research on street vending has grown exponentially in the field of sociocultural anthropology and sociology (M. Perelman 2013; Stillerman 2015; Shapiro Anjaria 2006). These bodies of study relate the vending phenomenon with urban poverty, unemployment and the dispute over the use of public space. However, to this date there exists no consistent research instrumenting analytic tools of linguistic nature which may lead to approach this topic as an eminently discursive phenomenon. The present study offers a tentative analysis of the so-called «street vending discourse» (in Spanish, «discurso comercial ambulante», DCA) and of the «begging discourse» («discurso mendicante», DM), both types of discourse being produced on the «Roca» train line, a means of public transport widely used by those commuting everyday from the southern outskirts of Buenos Aires to the City of Buenos Aires. This article has a two-fold goal: 1) build an understanding of DCA and DM as two associated discourse genres, subject to their own functional principles, their discursive conventions and material conditions; 2) account for the recurrent appearance of five discursive resources put into play in the DCA: a) the greeting, b) the apology, c) the token of gratitude, d) the technical description of the product, e) the assessment of the product. Drawing on a collection of 73 transcriptions of recorded interactions, the offered analysis focuses on the conditions of production of the street vending discourse and the begging discourse, as well as their presuppositions (Hayati y Maniati 2010; Olaosun 2008), the aspects regarding the interaction with the audience of passengers (Goffman 1979), the symbolic and material violence exerted by these types of discourse, as well as the deployment of discursive strategies aiming at the persuasion of purchase. The existing scale of products whose selling requires variable amounts of argumentative effort, the use of cataphor, the repertoire of formulae organized under a relatively conventional rhetorical structure, the commercial and advertising register, the intromission of TV advertising as authority quote, as well as particular linguistic usages and the presence of apology -all draw, according to our corpus, a series of structural, formal and functional regularities, both stable and flexible, leading to suggest the existence of street vending as a discursive genre (Briggs and Bauman 1996).

KEYWORDS: street vending discourse, argumentation, discourse analysis, street vending. 


\section{INTRODUCCIÓN}

Dados el precio del pasaje y el tiempo de duración del viaje a la Ciudad de Buenos Aires, el ferrocarril Roca es el medio de transporte más corriente de los trabajadores y sectores populares del sur del Gran Buenos Aires. Las rutinas del viaje configuran no solo grupos más o menos estables de personas que usan y habitan este espacio conjuntamente, sino modos de hacerlo según el horario, el día de la semana, la época del año, la finalidad, el destino, etc.

La venta ambulante ha recibido, en los últimos años, un tratamiento teórico desde la antropología sociocultural y la sociología. Existen estudios actuales centrados en perspectivas etnográficas (Perelman 2013a, 2013b, 2014) que estudian la actuación de estos agentes en el campo y el estatus contradictorio de su labor entre el trabajo/no trabajo, legalidad/ilegalidad. Shapiro Anjaria (2006, 2011) y también Stillerman (2006) problematizan las políticas del espacio, y la dinámica de la lucha por el uso del espacio público entre vendedores ambulantes y agentes del Estado. En general, estos estudios se interesan por la venta ambulante en tanto fenómeno vinculado estrechamente con la pobreza urbana, el desempleo y el espacio público en un escenario globalizado. Y a pesar de su prominencia creciente en los últimos años, no existe a la fecha un caudal consistente de abordajes teóricos que sitúe el problema en el campo del análisis del discurso y que instrumente herramientas analíticas de tipo lingüístico.

Los estudios de análisis del discurso y retórica que efectúan un tratamiento sistemático de esta producción discursiva se han focalizado sobre el discurso de mendigos ambulantes en Irán (Hayati y Maniati 2010) y sobre la venta ambulante en Nigeria (Olaosun 2008). Por su pertinencia temática y analítica, partimos de algunas de las conclusiones que estos trabajos arrojan, y en lo sucesivo las presentamos.

Hayati y Maniati (2010) parten de la observación de que para los mendigos ambulantes, el éxito del carácter persuasivo de su discurso constituye un elemento crucial, ya que de ello depende el cumplimiento del objetivo económico. Los autores plantean un análisis de cinco discursos ambulantes y emplean el modelo de Labov y Waletzky (1967) de narrativas de experiencia personal. El discurso ambulante, tomado entonces como narrativa de vida, asume una serie de particularidades estructurales que permiten manipular el material verbal y explicar su motivación retórica. Por otro lado, indagan sobre el posicionamiento de los oradores en relación con la audiencia, y postulan una noción de la narrativa como un espacio de construcción social:

Storytelling is a relational activity that gathers others to listen and empathize. It is a collaborative practice, and assumes tellers and listeners/questioners interact in particular cultural-historical contexts essential to interpretation. 
Analysis in narrative studies opens up forms of telling about experience, not simply the content to which language refers (Hayati y Maniati 2010: 44).

Además, sostienen que estos discursos ambulantes son de carácter público, y advierten que en la técnica de recolección de datos empleada se logra superar la paradoja del observador (Llamas y Stockwell 2002: 160, citado en Hayati y Maniati 2010), porque los sujetos desconocen el hecho de que su propia producción está siendo registrada, y el consentimiento se obtiene a posteriori.

El trabajo de Olaosun (2008) plantea como objetivo dar cuenta del funcionamiento retórico del discurso de los llamados «publicistas» de transporte, y demostrar que el lenguaje publicitario persigue, entre otros propósitos, conmover, entusiasmar y mentir. Estas y otras funciones constituyen el valor total de la producción oratoria de los vendedores ambulantes. El lenguaje que construye este tipo de discurso tiene una naturaleza eminentemente persuasiva y tiene por fin «ganarse al público». Para indagar sobre este punto, el estudio de Olaosun instrumenta el modelo de análisis del evento comunicativo, tal como fuera introducido por Dell Hymes (1974).

En una situación de venta típica, la audiencia solo escucha y no colabora con el desarrollo oratorio del vendedor/publicista. Entre las propiedades del discurso de los vendedores ambulantes, se destaca el juego de palabras, la repetición o duplicación léxica, la remisión a nombres propios prestigiosos (o «amplificación»), la broma y la intimidación al pasajero.

Por otra parte, la imagen social del vendedor ambulante es altamente negativa: la sociedad considera que son personas que han fracasado en todo. Sin embargo, el estigma que acompaña su rol convive con la imagen inversa, ya que los vendedores tienen también la reputación de ser grandes trabajadores.

En síntesis, tanto en Hayati y Maniati (2010) como en Olaosun (2008) se concibe el discurso ambulante como un tipo discursivo centrado sobre la persuasión, y de carácter público. Los abordajes metodológicos empleados sitúan el análisis en la sociolingüística y la psicología, y en los estudios retóricos y la etnografía del habla, respectivamente.

En el ámbito de los estudios del discurso en América Latina, se destaca el trabajo de Mónica Zoppi-Fontana (2005), quien explora la afirmación de los vendedores ambulantes brasileños en la calle como identidad socialmente legitimada. Para ello, analiza los procesos de identificación referentes a los camelôs en enunciados obtenidos de medios de comunicación y legislación municipal de Campinas, Brasil. El discurso de los vendedores ambulantes aparece en entrevistas hechas a sus dirigentes sindicales.

Zoppi-Fontana indaga los efectos de exclusión y discriminación cristalizados en los procesos de designación y usos de la modalidad deóntica, que operan en el equívoco entre criminalidad y marginalización. Luego, retoma los procesos discursivos analizados para observar sus ecos en enunciados 
de los camelôs, donde halla una fijación de los mecanismos de auto-referencia en un «discurso de la supervivencia» relacionado con lo provisorio y lo ilegítimo. Negar los efectos de exclusión social del discurso con el que los vendedores polemizan constituye, según Zoppi-Fontana, una trampa discursiva que atrapa al locutor en las mismas categorías definitorias que producen la exclusión. Sin embargo, la autora también encuentra en los textos analizados vestigios de procesos de identificación que señalan otra posición de sujeto, positiva y legítima en relación con el espacio urbano, y que se materializan en estructuras semántico-discursivas divididas y en la modalidad factual.

Sneider Saavedra Rey (2014) aborda, desde lo que llama un modelo pragmático-retórico, un corpus de trece discursos de vendedores y vendedoras ambulantes, quienes desarrollan su actividad en los buses de Bogotá. El autor expresa que estos actos de habla son constitutivos de los marcos cognitivos de los ciudadanos, releva la aparición de figuras retóricas que correlaciona directamente con la efectividad perlocutiva de los discursos en términos de éxito de venta, y menciona la recurrencia de algunos elementos que también se hacen presentes en nuestras muestras, como las fórmulas estereotipadas y los esquemas estructurales que califica como «guiones». Entre sus conclusiones fundamentales está la comprobación de que la figura retórica más rentable para el vendedor ambulante es la amplificación (explícita o tácita), por la cual el hablante se aparta de su objeto de venta para realzar cuestiones personales y familiares que conmocionen a su auditorio, respecto del cual busca una diferenciación, pues para la comunidad esa compra es considerada un favor o una colaboración.

De la lectura de los ejemplos presentados por Saavedra Rey se desprende una serie de divergencias con respecto a nuestro análisis, vinculada con la naturaleza disímil de los corpus: mientras que en Colombia la venta ambulante parece hibridarse con lo que en este trabajo caracterizamos como discurso mendicante, en Argentina el vendedor ambulante parece haber construido para sí una figura legitimadora relacionada con el trabajo y sus prácticas discursivas habitualmente se distancian de aquellas asociadas a la mendicidad.

En el presente estudio, presentamos una aproximación al abordaje de la venta ambulante y de la mendicidad como fenómenos eminentemente discursivos, pasibles de identificarse como instancias de ejecución o «performance» (Bauman 2002). En efecto, partimos de la presunción de que estos discursos constituyen modos totales de comunicación, y conforman un «marco distintivo, disponible como recurso comunicativo conjuntamente con los demás para los hablantes de las comunidades particulares» (2002: 29). En particular, la performance pone en juego un repertorio de recursos altamente convencionalizados y culturalmente específicos que permiten que la comunidad la reconozca como tal. Bauman enumera una 
serie de medios comunicativos documentados en diversas culturas, tales como los códigos especiales empleados específicamente para la ejecución, las fórmulas particulares que indican apertura o cierre convencionales, el lenguaje figurativo, las pautas prosódicas (el tempo, el acento, el tono), las pautas paralingüísticas relativas a la producción vocal, entre otros. A su vez, este dispositivo formal y corriente de recursos pone en funcionamiento la captación del auditorio, y permite establecer un marco de interpretación (Goffman 1974) para la performance en su totalidad. A los fines de este trabajo, al identificar la venta ambulante como una performance, asumimos que esta pone en juego un repertorio estable de recursos formales, cuya naturaleza convencional construye un marco distintivo y socialmente reconocible por la comunidad de pasajeros y vendedores del ferrocarril.

La producción y recepción de los discursos están siempre mediadas por la relación con discursos anteriores. En este sentido, entendemos los géneros discursivos como patrones históricos o modelos generalizados que orientan la producción y la interpretación discursivas. Como sostienen Briggs y Bauman (1996), el ajuste de un texto particular y su modelo genérico nunca es perfecto. Los textos de algunos géneros logran una transparencia genérica minimizando la distancia respecto de sus precedentes genéricos, mientras que otros se componen según estrategias de maximización de la fisura intertextual (1996: 91-92). Estos autores expresan una enérgica crítica a las perspectivas teóricas sobre el género «que afirman la existencia de rasgos inmanentes, y que sostienen la presencia de invariantes integradas en sistemas genéricos de gran consistencia interna y mutuamente excluyentes» (1996: 103) y proponen que las distinciones genéricas no se dan entre textos sino en las prácticas utilizadas para la creación de relaciones intertextuales con otros cuerpos textuales. Desde este punto de vista, la intertextualidad no es propiedad inherente a la relación entre texto y género sino a la construcción de esa relación.

«Las remisiones al género proporcionan estrategias eficientes para construir lo que Anderson llama "comunidades imaginadas" (Briggs y Bauman 1996: 92). Como veremos, vendedores y mendigos del tren tienden a gestionar de forma diferente la fisura entre sus performances y los correspondientes precedentes genéricos en función de las diferencias de sus objetivos retóricos.

\section{Metodología}

El artículo se plantea los siguientes objetivos:

1) situar el DCA y el DM como dos géneros discursivos asociados, sujetos a sus propios principios funcionales, sus convenciones discursivas y sus constricciones materiales; 
2) relevar la recurrencia de cinco recursos discursivos presentes en DCA:
a) el saludo,
b) la disculpa,
c) el agradecimiento,
d) la descripción técnica del producto, y
e) la evaluación del producto.

Por medio de un abordaje cuantitativo, se relevó la presencia o ausencia de estas instancias en un corpus de 73 muestras de audio recogidas entre los años 2016 y 2017, en viajes en tren de los ramales Glew/A. Korn, Ezeiza y Claypole de la ex línea de ferrocarril Roca. Los cinco recursos cuya frecuencia de aparición verificamos pueden dividirse en dos grupos. El primero reúne aquellos recursos que consideramos marcas rituales de cortesía, mecanismos de apertura del canal comunicativo y cuya presencia indica amenaza de la imagen (Brown y Levinson 1987): saludo, disculpa y agradecimiento. El segundo grupo -descripción técnica y evaluación del producto- engloba las apariciones de los principales argumentos de venta. En un apartado posterior al análisis de estos datos, efectuamos una descripción de rasgos de distinta naturaleza recurrentes en el DCA de los trabajadores informales del ferrocarril Roca.

La recolección de dicho corpus se realizó por medio de técnicas de registro y el almacenamiento de sonido en dispositivos móviles, la transcripción de las muestras y la asignación de un código de identificación único para cada una.

La instrumentación de esta metodología estuvo motivada por el interés de efectuar una descripción informada en una medición sistemática que permitiera echar luz sobre un conjunto de recursos propios de la estructuración del DCA. De esta manera, se pretendió superar una limitación en los estudios previos acerca del discurso de la venta ambulante, que parten de observaciones naturalistas del objeto, rara vez se preguntan por la frecuencia de los fenómenos que describen y proponen explicaciones exploratorias acerca del funcionamiento discursivo de este género.

\section{Resultados}

Observamos que, mientras el vagón del tren no esté repleto de personas que imposibiliten su tránsito, en general el vendedor ambulante demora, en la venta de un producto cuya exigencia argumentativa es baja, alrededor de 30 segundos en completar su performance. El promedio de duración de una muestra de nuestro corpus es de 1:03 minutos y en el 71,23\% de las muestras se comercializan productos comestibles. 
En la Tabla 1 se exponen los resultados arrojados por la medición de la frecuencia de aparición de recursos discursivos. En la columna izquierda, se presentan los cinco recursos discursivos que han sido analizados; las dos columnas siguientes muestran el resultado del relevamiento de la presencia o ausencia de estos recursos; la columna final expone los valores totales que conciernen a la medición.

Como se puede observar, los valores corresponden a las cantidades absolutas y a su expresión estadística en el procesamiento del corpus entero. Los apartados 2.1 y 2.2 acompañan la lectura de la Tabla 1 y ofrecen una interpretación de los datos obtenidos.

\subsection{Marcas rituales de cortesía: el saludo, la disculpa y el agradecimiento}

Del conjunto total del corpus, se verificaron 19 muestras encabezadas por saludos (un 26\%) y 54 muestras sin saludos (74\%). Este patrón se reitera en la categoría de la disculpa, en la que la cantidad de muestras sin segmentos apologéticos supera ampliamente el número de muestras con dichos segmentos. En particular, la medición arrojó 65 instancias de no disculpa $(89,1 \%$ del total) y 8 instancias de disculpa $(10,9 \%)$. Otro tanto sucede con el recurso de agradecimiento: en 66 muestras $(90,4 \%)$ hay ausencia del recurso, mientras que en un margen de 6 muestras se verifica su presencia (el restante $9,6 \%$ ).

TABLA 1. Medición de la frecuencia general de aparición de recursos en el DCA

\begin{tabular}{|c|c|c|c|}
\hline RECURSO & Presencia & AusenCIA & Total \\
\hline \multirow{2}{*}{ Saludo } & 19 & 54 & 73 \\
\hline & $26 \%$ & $74 \%$ & $100 \%$ \\
\hline \multirow{2}{*}{ Disculpa } & 8 & 65 & 73 \\
\hline & $10,9 \%$ & $89,1 \%$ & $100 \%$ \\
\hline \multirow{2}{*}{ Agradecimiento } & 7 & 66 & 73 \\
\hline & $9,6 \%$ & $90,4 \%$ & $100 \%$ \\
\hline \multirow{2}{*}{ Descripción técnica del producto } & 58 & 15 & 73 \\
\hline & $79,5 \%$ & $20,5 \%$ & $100 \%$ \\
\hline \multirow{2}{*}{ Evaluación del producto } & 48 & 25 & 73 \\
\hline & $66 \%$ & $34 \%$ & $100 \%$ \\
\hline
\end{tabular}


La coherencia ordenada en la medición de estos tres recursos (el saludo, la disculpa y el agradecimiento) permite suponer de manera tentativa que existe una tendencia generalizada en el DCA a su omisión. El conjunto de los resultados revela que un gran caudal de muestras se desarrolla con relativa ausencia del saludo, el agradecimiento y la disculpa, y con alta frecuencia de descripción técnica y evaluación del producto de la venta. En un análisis global, se observa que el DCA irrumpe sin mayor despliegue de cortesía verbal, invadiendo, en mayor o menor medida según el caso, el espacio personal de los miembros del auditorio, forzados a permanecer en una interacción comunicativa cuya prolongación depende, como veremos, de su grado de resistencia a la persuasión del vendedor, es decir, a la compra.

\subsection{Recursos argumentativos: la descripción y la evaluación del producto vendido}

Con respecto a los dos recursos restantes, el procesamiento de las muestras demostró una frecuencia relativa mayor de instancias de descripción técnica del producto y de evaluación, lo cual se relaciona con el carácter argumentativo del DCA. Del total del corpus, se exponen aspectos técnicos del producto en 58 muestras $(79,5 \%)$, contra un total de 15 muestras sin comentario explícito de dichos aspectos (20,5\%; ver Tabla 1). En las instancias de evaluación, se totalizaron 48 muestras con juicios evaluativos acerca del producto (66\%), y 25 muestras sin juicio alguno (34\%; ver Tabla 1).

El análisis cualitativo indica que es posible establecer una escala de productos que se venden en el tren que requieren mayor o menor esfuerzo argumentativo y, correlativamente, mayor o menor volumen de habla y tiempo de duración de la performance. Podemos interpretar la no necesidad de argumentación como huella de una doxa que caracteriza como normal y aceptada la compraventa de ciertos alimentos, y que hace cargar con el peso de la prueba al hablante que vende productos más alejados de los convencionales. En el extremo no-convencional de la escala ubicamos los productos más costosos y no comestibles (en nuestro corpus: música, películas, artículos electrónicos, de ferretería y de librería).

\subsection{La duración}

Una de nuestras premisas iniciales consistía en sostener que si nos centrábamos en este segmento de la escala en que el costo y el carácter «novedoso» del producto vendido exigen mayor esfuerzo argumentativo al vendedor ambulante, la frecuencia de aparición de los recursos analiza- 
dos adquiriría mayor relevancia. Para comprobarlo, seleccionamos todas las muestras con una duración mayor a un minuto. Estas representan el $27,39 \%$ del corpus y la incidencia de los discursos de venta de productos comestibles se reduce al $30 \%$.

En la Tabla 2 se exponen los resultados arrojados por la medición de la frecuencia de aparición de los cinco recursos discursivos en las muestras de DCA que exceden el minuto de duración total. En la columna izquierda, se disponen los cinco recursos discursivos analizados; las dos columnas siguientes exhiben el resultado del relevamiento de la presencia o ausencia de estos recursos; la columna final expone los valores totales que conciernen a la medición. Como se puede observar, los valores corresponden a las cantidades absolutas y a su expresión estadística.

En aquellas muestras que exceden el minuto de duración, la frecuencia de los tres recursos que interpretamos como marcas de cortesía tiende a duplicarse (a mayor duración de la interacción, mayor riesgo de amenaza de la imagen), pero sigue sin alcanzar el $50 \%$.

En relación con el segundo conjunto de recursos, que engloba las apariciones de los principales argumentos de venta, los porcentajes de la frecuencia de ocurrencia también se incrementan, lo cual resulta esperable dado el aumento del volumen de habla.

Habiendo comprobado que, a pesar del incremento relativo de las marcas de cortesía y los argumentos de venta en los discursos más extensos y

TABLA 2. Medición de la frecuencia de aparición de recursos en los ejemplos de DCA de más de un minuto

\begin{tabular}{|c|c|c|c|}
\hline RECURSO & $\begin{array}{l}\text { PRESENCIA EN } \\
\text { DISCURSOS DE MÁS } \\
\text { DE UN MINUTO }\end{array}$ & $\begin{array}{l}\text { AUSENCIA EN } \\
\text { DISCURSOS DE MÁS } \\
\text { DE UN MINUTO }\end{array}$ & TOTAL \\
\hline \multirow{2}{*}{ Saludo } & 8 & 12 & 20 \\
\hline & $40 \%$ & $60 \%$ & $100 \%$ \\
\hline \multirow{2}{*}{ Disculpa } & 4 & 16 & 20 \\
\hline & $20 \%$ & $80 \%$ & $100 \%$ \\
\hline \multirow{2}{*}{ Agradecimiento } & 4 & 16 & 20 \\
\hline & $20 \%$ & $80 \%$ & $100 \%$ \\
\hline \multirow{2}{*}{$\begin{array}{l}\text { Descripción técnica } \\
\text { del producto }\end{array}$} & 19 & 1 & 17 \\
\hline & $95 \%$ & $5 \%$ & $100 \%$ \\
\hline \multirow{2}{*}{$\begin{array}{l}\text { Evaluación } \\
\text { del producto }\end{array}$} & 16 & 4 & 20 \\
\hline & $80 \%$ & $20 \%$ & $100 \%$ \\
\hline
\end{tabular}


complejos, la frecuencia de aparición de estos recursos en dicho segmento del DCA no varía radicalmente, se revela que el factor primordialmente argumentativo en la venta ambulante es la duración de la performance o el tiempo de exposición del auditorio al discurso de venta en sí mismo. Los casos que exhiben un contraste más pronunciado en su duración y complejidad son, por un lado, la chipa $^{1}$ y la bebida y, por el otro, la venta de artículos de ferretería, CD de música y películas. Es por eso que, en nuestro corpus, constituyen los extremos de una escala de productos que se ordena en función del esfuerzo argumentativo que su venta requiere. La característica más significativa de la argumentación desencadenada es su extensión temporal.

\section{DiscursividAdES EN El TRANSPORTE PÚBliCO: DCA Y DM}

Diariamente, cientos de personas desarrollan actividades en los trenes de Buenos Aires con la finalidad de procurarse un ingreso de dinero que les permita vivir o sobrevivir. Lo que todos ellos tienen en común es que ejercen esas actividades por fuera del mercado de trabajo formal. Sin embargo, existen claras diferencias entre los grupos de personas que se ganan la vida en el tren. En este trabajo nos remitimos a hacer una primera descripción del discurso comercial de los vendedores ambulantes del ferrocarril Roca, pero nos resulta ineludible la mención del discurso mendicante que circula en el mismo espacio. Lo que como usuarias regulares del ferrocarril Roca percibimos y como analistas podemos comprobar en el análisis de los discursos, Mariano Perelman (2013a) lo demuestra a través de la investigación etnográfica, sobre la base de entrevistas de campo. El autor sostiene que sin la contraposición con los mangueros (como los vendedores ambulantes llaman a los mendigos, según el autor) no es posible comprender «el modo en que los vendedores se construyen como trabajadores» (Perelman 2013a: 181). Así, la venta ambulante como trabajo legítimo es parte esencial de la configuración del ethos ${ }^{2}$ hombre trabajador de los buscas o buscavidas $^{3}$ y

${ }^{1}$ Vocablo guaraní. Se llama chipa o chipá a un pan pequeño de consumo popular en Paraguay y Argentina, hecho con almidón de mandioca, queso duro (chicharrón), leche, huevos, manteca y sal.

${ }^{2}$ La noción de ethos, proveniente de la retórica griega, refiere a la imagen que el orador construye sobre sí mismo en el discurso, y constituye, al igual que el logos y el pathos, una prueba técnica por medio de la cual se logra la persuasión del auditorio. Esta categoría de análisis ha sido recuperada por el Análisis del Discurso en los años ochenta.

${ }^{3}$ Buscavidas o busca es un vocablo popular que designa al individuo que no dispone, por el motivo que sea, de un trabajo formal y se las ingenia llevando adelante actividades ocasionales (en general, venta ambulante) para ganarse la vida. 
golosineros y se construye a partir de la oposición con los mendigos o mangueros. Esta diferenciación es construida no solamente desde lo lingüístico sino también desde la vestimenta, el movimiento corporal, la toma o no de la palabra, el tono y el volumen de la voz, entre otros aspectos.

Mientras que «en los que piden [...] la puesta en escena de una "condición habilitante" para no estar trabajando es central» (Perelman 2013a: 182), resulta habitual que cuando se manifiesta un conflicto en el vagón, especialmente un conflicto por el espacio en los horarios pico, los vendedores esgriman el argumento ético de estar trabajando para justificar por ejemplo una molestia o empujón. De manera que la actividad que ejercen es permanentemente enmarcada como comercial y laboral, tanto en los enunciados que componen su discurso promocional o de venta como en otro tipo de interacciones con el resto de los usuarios y entre otros vendedores.

Vendedores y mendigos desarrollan sus actividades en un espacio compartido, con el objetivo común de obtener dinero para su subsistencia durante una cantidad de horas similar, pero constituyen grupos bien diferenciados y reconocibles. El mendigo tiene la obligación de garantizar su «condición habilitante» para ejercer la actividad económica ilegítima de pedir, en contraposición con la de trabajar: una discapacidad, una enfermedad propia o de un hijo, un pasado carcelario o de drogadicción, etc. Debe demostrar que mendigar es su última y única opción y que ha agotado todas las demás, excepto robar, que es a lo que supuestamente se vería empujado en caso de que los pasajeros no le brinden dinero.

En términos discursivos, la primera y más radical diferencia que el auditorio puede percibir entre vendedores y mendigos es el marco discursivo que ponen en funcionamiento. Si bien pedir y vender tienen como objetivo la persuasión del público y la obtención de un beneficio económico, la venta tiene asociada valores aceptables y remite al mundo del trabajo legítimo, aunque en este caso, informal. Pedir, por su parte, es considerada una acción vergonzosa y apenas aceptable en aquellos que demuestran alguna carencia que los hace merecedores de asistencia dada su imposibilidad de trabajar. En la súplica y la manifestación exhaustiva del sufrimiento por parte del mendigo se conjuga la garantía de la existencia de la condición que los habilita a pedir (ethos mendicante) con una fuerte apelación al pathos cuya finalidad es producir una conmoción tal que movilice al auditorio a darle dinero al mendigo. Las interacciones mendicantes más exitosas en términos retóricos son aquellas que pueden poner en escena un grado de novedad en el discurso ritualizado de la súplica, que desgasta el carácter de excepcionalidad y boicotea el efecto conmocionante del discurso.

Otra estrategia importante del discurso mendicante es la generación de un efecto de verdad a partir de la presentación de pruebas que docu- 
mentan la «condición habilitante» para pedir: certificados médicos, cajas de medicamentos, niños con deformidades, incluso la exhibición de la vestimenta. Un vocabulario técnico refuerza la demostración: designación completa de las instituciones en que se atienden, nombre de autoridades, designación precisa de medicamentos específicos para el tratamiento de sus patologías, dirección exacta de la granja o pensión en la que viven, entre otros. Estas estrategias responden a una dimensión polémica del discurso mendicante en los trenes de la cual el mendigo se hace cargo y que intenta neutralizar anticipándose a posibles objeciones (del tipo «¿por qué no trabaja en lugar de pedir?») o fracasos retóricos (por ejemplo, que el auditorio cuestione la veracidad de su condición habilitante para pedir).

Otros mendigos desarrollan su actividad en los vagones en absoluto silencio, repartiendo tarjetas con ilustraciones que ofrecen como contraprestación a la limosna. La mayoría de las veces, repartan tarjetas o no, el mendigo silencioso reemplaza la performance oral por un mensaje escrito en un papel pequeño en el que solicita una colaboración y brinda alguna razón para hacerlo. Más adelante, podemos ver algunos ejemplos.

Con excepción de las personas sordomudas, el silencio funciona como gesto de humillación, anulación, sumisión, tendiente a afectar la sensibilidad del pasajero y en línea con la concepción de ilegitimidad de la acción de mendigar en contraposición con la legitimidad del trabajo.

Por último, hace relativamente pocos años los mendigos del tren Roca, sobre todo los menores, han comenzado a solicitar a los pasajeros un saludo con la mano o, menos frecuentemente, un beso en la mejilla. El contacto físico genera un compromiso personal mayor al poner mucho más

FiguRA 1. Ejemplo de discurso mendicante, a partir de un mensaje escrito

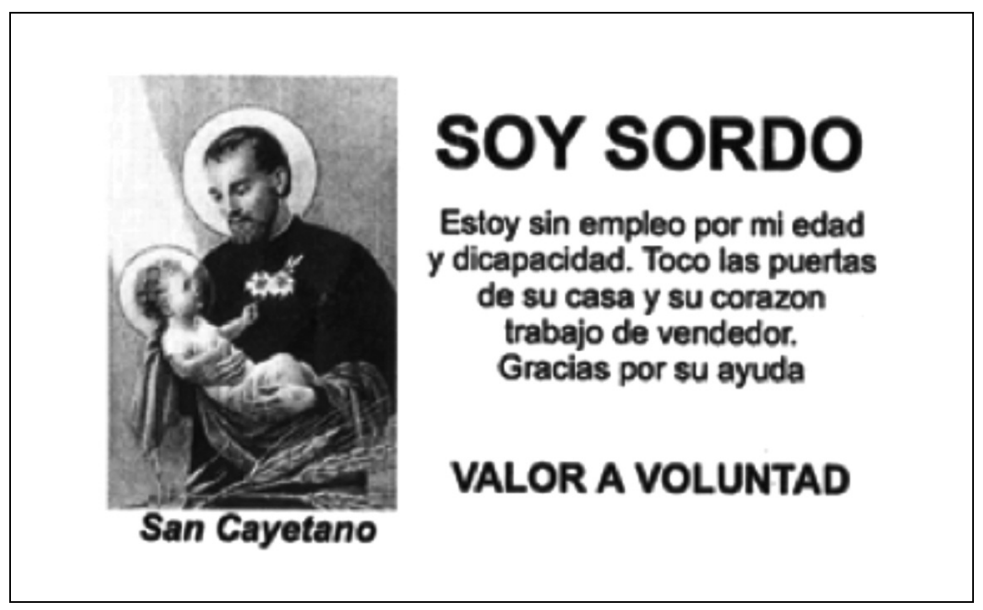


FIGURA 2. Ejemplo de discurso mendicante, a partir de un mensaje escrito

Sres. Pasajeros disculpe las molestias soy sola con mi be be de 1 añoy medio. Ella debido a su prematures iequiere de oxigeno Permaneit y reabilitación... vivimos alquilando una Pieza les Pedimos su colaboración para Poder cubrir Las necosida des Lemi hija... Grasies.

en riesgo la imagen del interlocutor, instalando la necesidad de una respuesta verbal por parte del usuario, que debe acceder a la invasión de su espacio personal por un extraño o incurrir en la descortesía de decir «no», por ejemplo, cuando se le quiere dar la mano (en términos pragmáticos, el saludo es un par adyacente). Según Erving Goffman (1959, 1979), todo aquello que le pertenece o se relaciona con el participante de una interacción, es algo cuya valoración le importa. Su imagen social o face se pone en juego en la elección de la cortesía. De esta manera, el mendigo fuerza la apertura del canal comunicativo en un gesto que el usuario puede vivenciar como violento pero cuya violencia es contrarrestada por la empatía facilitada por la condición habilitante a la mendicidad del que pide.

\section{El discurso COMERCial ambulante}

El discurso del busca y el golosinero en el vagón tiene por objetivo la venta de un producto. La actividad discursiva que se pone en juego en la venta ambulante implica una habilidad, una pericia discursiva: el arte verbal. El de los vendedores ambulantes del tren es un discurso oral formulado en un tono elevado, en general a partir de una impostación de la voz, para obtener mayor sonoridad en un espacio ruidoso y ante un público que, aunque espacialmente cautivo, no entra voluntariamente en la interacción 
ni demuestra especial interés por ella. A diferencia de la venta ambulante y callejera en otras regiones de América Latina, en Buenos Aires esta no incluye el «regateo ${ }^{4}$ : los precios de los productos están estandarizados y surgen de acuerdos más o menos explícitos entre vendedores, de acuerdo con los costos, la rentabilidad y el poder adquisitivo que atribuyen al público usuario del tren, y no de una negociación verbal con el cliente-pasajero.

Existe un comportamiento comercial estratégico que contempla, fundamentalmente, la variable tiempo. Esto es, no se vende cualquier cosa a cualquier hora: hay horarios diferenciados para la venta de determinados productos (café por la mañana, panchos ${ }^{5}$ durante el horario de la comida). Además, la oportunidad de venta también se fija en relación con determinadas épocas (vacaciones de invierno, día del niño, de la madre, Navidad).

La toma de la palabra para la performance de la venta (lo que los vendedores y mendigos llaman «hacer el vagón») es asumida en un sistema de turnos y es el derecho al que se accede, según Mariano Perelman (2013a), a través de la construcción colectiva del territorio:

Se dividen por horarios, por ramales, por tareas/productos y se organizan para que nuevas personas puedan o no trabajar en los trenes. [...] En el caso de la venta ambulante, una relación de confianza basada en el saber que la otra persona tiene códigos es central para poder participar en la venta. [...] Así, para trabajar sin problemas y que otros vendedores respeten el territorio ganado y reconocido, los buscas deben abocarse a trabajar en su espacio y ser confiables (Perelman 2013a: 190-191).

En relación con su estructura, la intervención del vendedor ambulante se suele componer de:

- Un inicio en el que saluda a los pasajeros o llama su atención (puede incluir un segmento apologético).

- Una presentación del producto que ofrece (qué es y de qué marca).

- El desarrollo de los argumentos de venta (bajo precio, utilidad, exquisitez, novedad, calidad, renombre, etc.).

- Un cierre evaluativo de la oferta en el que se destaca su carácter excepcional.

- Una coda o una especie de vuelta al inicio que recoge las señas del producto que son más importantes para elaborar la imagen (pareciera tratarse de un remate discursivo que retoma tres elementos: la mención del producto, una característica distintiva y el precio).

\footnotetext{
dedor.

${ }^{4}$ En el regateo, el comprador solicita rebajar el precio de un bien o un servicio al ven${ }^{5}$ Perrito caliente o hot dog.
} 


\subsection{El uso retórico de la catáfora}

Muchas veces el desarrollo de los argumentos de venta comienza antes de la mención del producto vendido, como forma de generar suspenso e interés por él. El empleo de la catáfora produce expectativa por el producto, tal como destacamos en los siguientes fragmentos:

Muestra 3: LAPICERAS BIC 02:00 min

Bueno, qué tal

Cómo le va

Buenos días para todos

Mire, lo que les traigo les va a venir bárbaro

Si tiene chicos en la edad escolar o para uso personal

Excelente lapicera Bic la que les traigo

$[\ldots]$

Muestra 4: MECHAS 03:00 min

Bueno, caballeros, damas

Ante todo

Les voy a pedir un millón de disculpas, mire

Por la molestia ocasionada

Muy buen viaje

Prosperidad para todos

Mire qué notable la oferta que le voy a entregar en el día de hoy

Señores, les entrego en esta oportunidad, mire

Si usted tiene máquina agujereadora eléctrica

Les entrego mechas, señores

Mechas de acero rápido

$[\ldots]$

Muestra 6: HAMBLET 0:22 min

Para deleitar mientras viaja, llevar a los más chicos

Son chocolates Hamblet

[...]

Muestra 8: CARAMELOS TIMBO 0:39 min

Buenas tardes, damas y caballeros

Mire, salió hoy a la venta

Clásicas y tradicionales

Caramelos Timbo

$[\ldots]$

Muestra 10: ALFAJORES SUSCHEN 1:07 min

Para disfrutar mientras que viaja o para llevarle a los chicos

Para regalar, quedar más que bien

Riquísimos alfajores triples

Estos son alfajores Suchen de dulce de leche.

$[\ldots]$ 


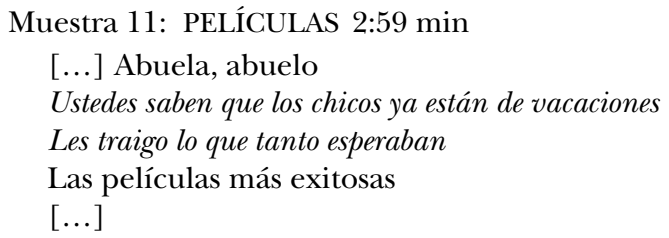

Entre el cierre evaluativo de la oferta y la coda, que se repite hasta el final de la intervención del vendedor en el vagón, este abandona el punto espacial en el que tomó la palabra y comienza a recorrer el vagón repitiendo la coda y ofreciendo el producto por las hileras de asientos, en un tono más rutinario y absolutamente atento a la gestualidad de los posibles compradores.

\subsection{El carácter oral del DCA}

Como enunciados de la memorización y repetición oral (Ong 2011), las intervenciones de los vendedores ambulantes no solo son estables estructuralmente. Además, están fuertemente marcadas por elementos deícticos y están compuestas sobre un esqueleto discursivo como el que describimos, que se «rellena» con fórmulas de un repertorio compartido y otros recursos retóricos en función del producto que se ofrezca eventualmente. Por ejemplo, si el producto es de una marca líder en el mercado, el vendedor asegura al usuario que «lleva marca, lleva calidad». Si no lo es, aludirá a él como «fino, rico y exquisito», por ejemplo, o insistirá en la relación precio-cantidad o en el carácter excepcional de la oferta: «si tiene y puede, no se lo pierda».

Una de nuestras grabaciones es especialmente reveladora de la forma en que los vendedores construyen su performance. La situación se dio un día de semana en un horario no pico. Varios vendedores habían ya «hecho el vagón» y aguardaban a que el tren llegara a la próxima estación para trasladarse rápidamente por el andén al siguiente vagón ${ }^{6}$. El último de la serie de vendedores que hizo ese vagón, comenzó desganado su performance con el saludo y la disculpa ritual, pero luego la abandonó, en un gesto jocoso, cómplice con los otros vendedores.

Muestra 5: BLA BLA BLÁ 0:40 min

Hola, ¿cómo le va? Buenas tardes, perdone la molestia, o por todas las molestias que le pueda llegar a ocasionar en este viaje

\footnotetext{
${ }^{6}$ Los trenes eléctricos Toshiba del ferrocarril Roca tienen seis vagones, divididos en dos bloques de tres vagones cada uno, a lo largo de los cuales el usuario puede transitar internamente, pero para pasar de un bloque a otro es necesario descender del tren en una estación y volver a ingresar por otro vagón.
} 
Hoy lo voy a molestar un minuto por este medio

Depende cuánto me dure la propaganda

Mire, el otro... entré ahí... en el otro vagón haciendo la misma propaganda

Hablando las mismas pelotudeces

Sé que ustedes no me están escuchando

Porque no me están dando bola

Porque están escuchando música

Bla bla blá, bla bla blá

Dos por diez

¿Bla bla, bla blá?

Bla bla blá

Bla blá

Bla bla blá, bla bla blá

Esta intervención totalmente atípica demuestra, por su desviación respecto del género discursivo:

1) La importancia que el vendedor otorga al tiempo de duración de la performance como elemento persuasivo determinante de la venta y a la vez como puesta en riesgo de su imagen, puesto que el segmento apologético está ligado a la interrupción y la brevedad del tiempo que promete asignar a la interacción.

2) El esfuerzo centrado en la apertura y sostenimiento del canal comunicativo en una interacción en la que una de las partes no manifiesta cooperación.

3) La existencia de una estructura que habitualmente se rellena con fórmulas y argumentos de venta eventuales en función del producto que se esté vendiendo en ese momento (en este caso, vacantes y representados por el «bla bla bla»).

4) La asociación de la propia actividad discursiva al discurso publicitario (en Argentina usualmente aludido como «propaganda»).

\subsection{El DCA y su vínculo con la publicidad}

En el discurso de los vendedores ambulantes, la publicidad televisiva no solo constituye un modelo genérico sino que también es citada como autoridad que legitima el producto y el enunciado del hablante.

Muestra 11: PELÍCULAS 2:59 min

$[\ldots]$

Les traigo lo que tanto esperaban

Las películas más exitosas

La era del hielo 5, señores

Todo el formato dvd 
No están grabados en el cine

Mire, esta película tiene propaganda televisiva

Tengo Buscando a Dory, otra película exitosa para los chicos $[\ldots]$

Muestra 51: CITOS 01:03 min

Para regalar, regalarse, quedar más que bien con muy poco, se ha puesto a la venta

finos, ricos y exquisitos, son los nuevos Citos elaborados por Arcor.

Los mismos tienen propaganda televisiva.

$[\ldots]$

Algunas de las huellas de la dialéctica entre la variedad de lengua del hablante y el modelo genérico de la publicidad son las siguientes alternancias:

- Léxicas (por ejemplo, en el uso del verbo deleitar por degustar, con carácter transitivo, en fórmulas como "para deleitar en el viaje o llevar de regalo»).

- Fonológicas (por ejemplo, en la pronunciación hamler o hamblet por hamlet para mencionar la marca de chocolates).

- De registro (por ejemplo, en el uso del vocablo estuche por envase para referirse al envoltorio de una golosina).

Estos deslizamientos constituyen marcas que caracterizan el género discursivo que llamamos discurso comercial ambulante.

Este registro comercial-publicitario propio del discurso ambulante se caracteriza por una cortesía ritual, por ejemplo, en el empleo del vocativo «señora», «señor» y el uso del imperativo de tratamiento formal (generalmente, «mire»), cuya operatividad es formulaica y a la vez constituye una invitación a participar de la interacción. Su función es la de abrir un canal que está en principio cerrado y mantener la atención necesaria para persuadir. Además, hay elementos de una suerte de discurso local («este medio de transporte»), un gran conocimiento presupuesto acerca del destinatario y proliferación de elipsis, en especial verbales, que dan cuenta de una importante cantidad de sobreentendidos compartidos por los usuarios del tren y puestos al servicio de la legitimación de la oferta promocionada en la performance, dado que el objetivo retórico del DCA es siempre la persuasión para la venta.

\subsection{La función discursiva de la disculpa}

Una de las estrategias del discurso comercial ambulante es la inclusión de un segmento apologético ritual que encabeza la asunción del turno de 
habla por parte del vendedor. La práctica de registro nos permite establecer una generalización inicial: cuanto mayor es el costo interpersonal de la violación de la libertad del pasajero, mayor es la presión por inscribir un segmento apologético de carácter formal. Tal generalización es especialmente cierta en aquellos discursos cuya duración es prolongada, como el caso de la venta de CD, cuya promoción implica, según las condiciones actuales, la reproducción del material sonoro, a un volumen elevado, y por un período de tres a siete minutos. Si a estas condiciones de producción discursiva sumamos el monopolio del turno de habla y la imposibilidad por parte del pasajero de impugnar su cooperación en una interacción obligada, entonces la disculpa revela su necesidad argumentativa de atemperar en el plano del discurso la violencia que se ejerce de forma material.

A continuación presentamos algunos ejemplos, según el tipo de producto promocionado:

Muestra 2: CDS 5:58 min

Hola, qué tal,

Damas, caballeros

Mil disculpas por las molestias ocasionadas con el sonido de la música

Compilado bárbaro formato mp3

Con todo lo nuevo, lo último y lo mejor 2016

$[\ldots]$

Muestra 4: MECHAS 3:00 min

Bueno, caballeros, damas

Ante todo

Les voy a pedir un millón de disculpas, mire

Por la molestia ocasionada

Muy buen viaje

Prosperidad para todos

Mire qué notable la oferta que le voy a entregar en el día de hoy

Señores, les entrego en esta oportunidad, mire

Si usted tiene máquina agujereadora eléctrica

$[\ldots]$

Muestra 20: AGENDA CITANOVA 01:22 min

Hola, buenas tardes.

Perdone la molestia.

Para agendar todo tipo de anotaciones,

números importantes, direcciones de email,

van a llevar agendas 2016 de la marca Citanova.

$[\ldots]$

Muestra 50: ALFAJORES GENIO 0:25 min (niño)

Señor pasajero, disculpe la molestia.

Para llevarle de regalo a sus hijos les traje alfajor relleno con dulce de leche 
Van a abonar los tres alfajor triple relleno con dulce de leche nada más que diez pesos van a abonar Alfajor triple van a abonar diez pesos.

Muestra 67: MÚSICA CRISTIANA 03:21 min

Bueno, ahora sí, hola, qué tal, ¿cómo le va, dama, caballero?

Rapidito, voy a molestar, interrumpir unos segunditos, ante todo, buen día, buen viaje.

Mire, sin lugar a duda, un compacto bárbaro el que les traigo. $[\ldots]$

Una primera lectura de estos ejemplos permite verificar que la inscripción apologética se vincula, asimismo, con la emergencia de un registro elevado, a partir del tratamiento de respeto (dama, caballero; uso del pronombre de tratamiento formal usted) y de fórmulas de saludo. La disculpa se inscribe en un patrón regular formado por una tríada discursiva: saludo, interpelación cortés al pasajero, disculpa; todo lo cual configura la apertura formal del discurso y permite, en un primer momento, intentar vencer la resistencia a su irrupción.

Según R. Lakoff (2001), tanto en el nivel formal como en el performativo, la disculpa tiene un componente de ambigüedad. Lakoff enumera nueve niveles de análisis para el abordaje discursivo de la disculpa, y sostiene:

Apology is always face-threatening for the speaker; but not making a necessary apology may occasion more serious face loss in the long run. As Brown and Levinson (1987) would say, the weightiness of a contemplated apology as a face threat must be computed by giving consideration to the intimacy and power relationships of the parties involved, and the seriousness of the misdeed that occasioned it (Lakoff 2001: 211-212).

La disculpa en el discurso comercial ambulante y mendicante es, en principio, una amenaza para la propia imagen del vendedor y el mendigo. Sin embargo, su inclusión juega un papel retórico en discursos extensos al modo de la captatio benevolentiae, porque el presupuesto lógico de la disculpa (esto es, la implicación de que se ha obrado mal) permite hacer una transición inmediata al verdadero corazón del discurso comercial ambulante: la promoción del producto.

La disculpa funda una relación entre los participantes en la que el vendedor reconoce, aunque sea artificial y formalmente, que su propio accionar cuenta como una coerción del principio de libertad interpersonal de su auditorio. En definitiva, se trata de una estrategia: la disculpa crea la ficción discursiva de que el vendedor empatiza con el pasajero, cuando las condiciones que rigen la situación discursiva permiten afirmar un gesto de cuño contrario. 
Los estudios pragmáticos clásicos (Searle 1974) atribuyen a la fórmula de disculpa la asunción de una responsabilidad; sin embargo, no hay en el DCA una disculpa que suponga una puesta en riesgo efectiva de la propia imagen porque, en todo caso, la responsabilidad se asume, efímera y superficialmente, en el plano del discurso.

\section{Palabras finales}

En este artículo llevamos a cabo un trabajo descriptivo de dos tipos discursivos que llamamos discurso comercial ambulante (DCA) y, por contraposición, discurso mendicante (DM), propios los dos del espacio público del ferrocarril Roca. Nuestros objetivos eran: identificar las particularidades del DCA de los trabajadores informales de la línea Roca y proponer un análisis centrado en los recursos discursivos que ponen en escena.

En relación con el primer objetivo de este estudio y a modo de síntesis, presentamos un esquema comparativo de los rasgos más distintivos que, de acuerdo con nuestro relevamiento, exhiben el DCA y el DM.

TABLA 3. Esquema comparativo de los rasgos distintivos del DCA y el DM

\begin{tabular}{|c|c|c|}
\hline $\begin{array}{c}\text { CRITERIOS } \\
\text { DE DESCRIPCIÓN }\end{array}$ & $\begin{array}{l}\text { DISCURSO COMERCIAL } \\
\text { AMBULANTE (DCA) }\end{array}$ & DISCURSO MENDICANTE (DM) \\
\hline $\begin{array}{l}\text { Marco } \\
\text { metacomunicativo }\end{array}$ & Trabajar. & Pedir. \\
\hline $\begin{array}{l}\text { Aceptabilidad } \\
\text { social }\end{array}$ & $\begin{array}{l}\text { - Legitimidad relativa. } \\
\text { - Relación basada sobre un } \\
\text { principio de reciprocidad, } \\
\text { dado por el intercambio } \\
\text { comercial de bienes. }\end{array}$ & $\begin{array}{l}\text { - Ilegitimidad. } \\
\text { - Relación basada sobre } \\
\text { un principio de donación, en el } \\
\text { que no hay contraprestación; } \\
\text { vinculación con la asistencia } \\
\text { social. }\end{array}$ \\
\hline $\begin{array}{l}\text { Fundamento } \\
\text { de la actividad }\end{array}$ & $\begin{array}{l}\text { Exclusión del mercado } \\
\text { de trabajo formal. }\end{array}$ & $\begin{array}{l}\text { Condición habilitante que } \\
\text { demuestre, mediante pruebas, } \\
\text { la imposibilidad de trabajar. }\end{array}$ \\
\hline $\begin{array}{l}\text { Lenguaje y tipos } \\
\text { discursivos } \\
\text { asociados }\end{array}$ & $\begin{array}{l}\text { - Lenguaje relativamente } \\
\text { concreto, impersonal. } \\
\text { - Apela a la inmediatez } \\
\text { de la oferta. } \\
\text { - Vinculado con el discurso } \\
\text { publicitario. }\end{array}$ & $\begin{array}{l}\text { - Lenguaje relativamente abstracto, } \\
\text { afectivo, religioso, personal. } \\
\text { - Apela a la solidaridad del público. } \\
\text { - Vinculado con las narrativas } \\
\text { de experiencia personal } \\
\text { (Labov y Waletzky 1967). }\end{array}$ \\
\hline
\end{tabular}


TABLA 3. (cont.)

\begin{tabular}{|c|c|c|}
\hline $\begin{array}{c}\text { CRITERIOS } \\
\text { DE DESCRIPCIÓN }\end{array}$ & $\begin{array}{l}\text { DISCURSO COMERCIAL } \\
\text { AMBULANTE (DCA) }\end{array}$ & DISCURSO MENDICANTE (DM) \\
\hline $\begin{array}{l}\text { Temporalidad } \\
\text { construida } \\
\text { por el discurso }\end{array}$ & $\begin{array}{l}\text { El presente; lo inmediato. } \\
\text { «Acaba de salir a la venta...» }\end{array}$ & $\begin{array}{l}\text { Las modulaciones entre el pasado } \\
\text { y el presente. }\end{array}$ \\
\hline Contrafigura & $\begin{array}{l}\text { El mercado de venta } \\
\text { formal. }\end{array}$ & $\begin{array}{l}\text { El gobierno, la sociedad, } \\
\text { «las desgracias de la vida». }\end{array}$ \\
\hline $\begin{array}{l}\text { Relación } \\
\text { con el público } \\
\text { de usuarios }\end{array}$ & $\begin{array}{l}\text { Cercanía pretendida } \\
\text { con el usuario. } \\
\text { El vendedor presume } \\
\text { compartir con } \\
\text { el usuario la condición } \\
\text { de trabajador. }\end{array}$ & $\begin{array}{l}\text { Explotación de la distancia social } \\
\text { con el pasajero. }\end{array}$ \\
\hline \multirow[t]{2}{*}{$\begin{array}{l}\text { Modalidades } \\
\text { de realización }\end{array}$} & $\begin{array}{l}\text { Interpelación verbal } \\
\text { directa. }\end{array}$ & $\begin{array}{l}\text { 1. Interpelación verbal directa. } \\
\text { 2. Entrega silenciosa de mensajes } \\
\text { escritos. } \\
\text { 3. Búsqueda de contacto físico. } \\
\text { 4. Escenificación de micro- } \\
\text { espectáculos artísticos } \\
\text { (malabares, canciones). }\end{array}$ \\
\hline & $\begin{array}{l}\text { La permanencia en la } \\
\text { función contribuye a la } \\
\text { confiabilidad del ethos. }\end{array}$ & $\begin{array}{l}\text { La rotación o la movilidad } \\
\text { contribuye a la confiabilidad } \\
\text { del ethos. }\end{array}$ \\
\hline $\begin{array}{l}\text { Objetivo } \\
\text { discursivo }\end{array}$ & $\begin{array}{l}\text { Promover y persuadir de la } \\
\text { conveniencia práctica } \\
\text { del producto. }\end{array}$ & $\begin{array}{l}\text { Conmover emocionalmente, } \\
\text { construir un vínculo basado } \\
\text { sobre la empatía. }\end{array}$ \\
\hline $\begin{array}{l}\text { Prejuicios sociales } \\
\text { en torno } \\
\text { a la actividad }\end{array}$ & $\begin{array}{l}\text { - Cuestionamiento de la } \\
\text { calidad de los productos. } \\
\text { - Cuestionamiento del } \\
\text { origen de estos productos } \\
\text { (se presume que provie- } \\
\text { nen del contrabando). } \\
\text { - Rechazo del perfil social } \\
\text { y comunitario del } \\
\text { conjunto de vendedores. }\end{array}$ & $\begin{array}{l}\text { - Cuestionamiento hacia la premisa } \\
\text { de la pobreza o la imposibilidad } \\
\text { de trabajar. }\end{array}$ \\
\hline
\end{tabular}

Como ya hemos señalado, la diferencia más importante que distingue la actividad de los vendedores de la de los mendigos reside en el marco de interpretación que sus discursos fundan. En efecto, los vendedores conci- 
ben su actividad como trabajo y es justamente este marco metacomunicativo el que fundamenta la legitimidad de su rol y su relación con el público de usuarios: el vendedor presume compartir con el usuario una condición idéntica. Por otro lado, el discurso mendicante instaura un marco de interpretación diferente: el pedido de una donación. Al tratarse de una solicitud sin contraprestación alguna, necesita ampararse en una condición habilitante que justifique la imposibilidad de trabajar. Así, y contrariamente al DCA, el discurso mendicante construye su relación con el público al explotar la distancia social entre el mendigo y el usuario.

Además, hemos constatado que el DCA se vincula especialmente con el discurso publicitario en dos sentidos. En primer lugar, la remisión a la publicidad televisiva permite jerarquizar el producto y someter a examen el prejuicio social que cuestiona su calidad. En segundo lugar, pareciera que el DCA mismo se autodefine como un discurso publicitario; recordemos que en la muestra 5 («blablabla»), el vendedor continuará hablando lo que le dure «la propaganda», un gesto metadiscursivo que revela un grado fuerte de identificación genérica con el discurso publicitario. Por otro lado y tal como señalan Maniati y Hayati (2010), el DM se vincula con las narrativas de experiencia personal (Labov y Waletzky 1967), al ofrecer un relato autobiográfico que narra las circunstancias que conducen a la condición actual de pobreza. Además, mientras el DCA es un tipo discursivo que apela al presente y a la inmediatez (al presentar fórmulas tales como «este producto acaba de salir a la venta», «una oferta por varios días»), el DM teje profundas relaciones entre el pasado y el presente, y explora las modulaciones del tiempo.

Otro punto de interés para nuestro estudio es que la confiabilidad del DCA es proporcional a su estabilidad y permanencia en el ecosistema discursivo del ferrocarril. Es decir, observamos que los vendedores logran una transparencia genérica minimizando la distancia entre sus performances y el género del DCA. Obtienen así un discurso máximamente interpretable a la luz de sus precedentes genéricos (Briggs y Bauman 1996). Cuanto más visible y permanente sea el discurso de un vendedor, más confiable será su imagen frente al público de usuarios. En efecto, hay vendedores que aseguran al pasajero «usted ya me conoce y no me deja mentir», con lo cual refuerzan la familiaridad de su presencia discursiva y a su vez validan socialmente su actividad. Por otro lado, el DM parece exhibir una tendencia inversa: su confiabilidad y su éxito retórico son proporcionales a la novedad del discurso, tanto a la innovación de su contenido como a la de sus estrategias. En sentido opuesto al DCA, el DM maximiza las fisuras intertextuales con estrategias que rivalizan con los precedentes genéricos (Briggs y Bauman 1996). A diferencia del DCA, el DM no puede ejecutarse mucho tiempo sin sufrir un desgaste retórico; por ello, debe regenerarse periódi- 
camente, renovándose a sí mismo y variando su auditorio. En la práctica, esta renovación significa que los mendigos alternan su presencia en las distintas líneas de ferrocarril, lo cual les permite exponer su discurso frente a un nuevo público de pasajeros.

En relación con nuestro segundo objetivo, la identificación de particularidades discursivas del DCA, constatamos que la existencia de una gradación de productos que requieren mayor o menor esfuerzo argumentativo para su venta, el empleo de catáforas, el repertorio de fórmulas organizadas sobre una estructura retórica relativamente común, el registro comercialpublicitario, la cita de autoridad de la publicidad televisiva, ciertos usos lingüísticos peculiares y la disculpa configuran, según nuestro corpus, una serie de regularidades estructurales, formales y funcionales estables y a la vez flexibles que nos habilitan a sostener la existencia de un género discursivo de la venta ambulante (Briggs y Bauman 1996).

Estas conclusiones nos permiten proyectar posteriores abordajes del tema en materiales audiovisuales de otros géneros, como publicidades ${ }^{7}$ y pelí$\operatorname{culas}^{8}$ argentinas protagonizadas por vendedores ambulantes que otorgan al analista la oportunidad de relevar presupuestos subyacentes y estereotipos acerca de dicho colectivo, teniendo en cuenta que las marcas dejadas por la producción social del sentido en las materias significantes son una vía privilegiada para el análisis de las condiciones de producción y la dimensión ideológica de los discursos.

7 Vendedores ambulantes, Pack Arnet, 2009.

${ }^{8}$ El verso, Santiago C. Oves, 1995. 


\section{BIBLIOGRAFÍA}

BAUmAN, Richard (2002): «El arte verbal como ejecución», en Lucía Golluscio, La etnografía del habla: textos fundacionales, Buenos Aires: Eudeba, 117-150.

Bernal LinNersand, María (2007): Categorización sociopragmática de la cortesía y de la descortesía. Un estudio de la conversación coloquial española, Stockholm: Stockholm University.

BRIGGS, Charles L. y Richard BAUMAN (1996): «Género, intertextualidad y poder social», Revista de Investigaciones folklóricas 11, 78-108.

Brown, Penelope y Stephen Levinson (1987) [1978]: Politeness. Some Universals in Language Use, Cambridge: Cambridge University Press.

GOFFMAN, Erving (1994 [1959]): La presentación de la persona en la vida cotidiana, Buenos Aires: Amorrortu.

- (1974): Frame Analysis. An Essay on the Organization of Experience, Boston: Northeastern University Press.

- (1979): Relaciones en público. Microestudios del orden público, Madrid: Alianza Editorial.

HaYATI, Majid y Mahmoud ManiaTi (2010): «Beggars are sometimes the choosers!», Discourse and Society 21, 41-57.

LAKOFF, Robin (2001): «Nine Ways of Looking at Apologies: The Necessity for Interdisciplinary Theory and Method in Discourse Analysis». En Deborah Schiffrin, Deborah Tannen y Heidi E. Hamilton (eds.), The Handbook of Discourse Analysis, Malden MA: Blackwell Publishers Ltd, 199-214.

LABOv, William y Joshua Waletsky (1967): «Narrative analysis». En June Helm (ed.), Essays on the verbal and visual arts, Seattle: University of Washington Press, 12-44.

Olaosun, Ibrahim Esan (2008): «Two as Magic Number: Aspects of the Persuasive Style of Commercial Road Transport Advertising Discourse in SouthWestern Nigeria», The International Journal of Language Society and Culture 25, 73-81.

ONG, Walter (2011): Oralidad y escritura. Tecnologías de la palabra, Buenos Aires: FCE.

Perelman, Chaïm y Lucie Olbrechts-Tyteca (1989): Tratado de la argumentación. La nueva retórica, Madrid: Gredos.

Perelman, Mariano (2013a): «Trabajar en los trenes. La venta ambulante en la ciudad de Buenos Aires», Horizontes antropológicos 39, 179-204.

- (2013b): «Trabajar, pedir, vender. El caso de los vendedores ambulantes en trenes de la Ciudad de Buenos Aires, Argentina», The Journal of Latin American and Caribbean Anthropology 18/2, 231-250.

- (2014): «Viviendo el trabajo. Transformaciones sociales, cirujeo y venta ambulante», Trabajo y Sociedad 23, 45-65. 
Plantin, Christian (1998): «La interacción argumentativa», Escritos, Revista del Centro de Ciencias del Lenguaje 17-18 (enero-diciembre), 23-49.

SAAVEDRA REY, Sneider (2014): «El arte de conmover. Estudio retórico y pragmático sobre las ventas en los buses", Panorama de los estudios del Discurso en Colombia. Serie Eventos 2, 51-72.

Shapiro Anjaria, Jonathan (2006): «Street Hawkers and Public Space in Mumbai», Economic and Political Weekly 27, 2140-2146.

- (2011): «Ordinary states: Everyday corruption and the politics of space in Mumbai», American Ethnologist 38/2, 58-72.

Stillerman, Joel (2006): «The Politics of Space and Culture in Santiago, Chile's Street Markets», Qualitative Sociology 29/4, 507-530.

Zoppi-Fontana, Mónica (2005): «Identidades (in)formales. Contradicción, procesos de designación y de subjetivación en la diferencia», Versión 14, 13-57. 